\title{
INSPIREE:
}

\section{Metode Drill Dalam Peningkatan Keterampilan Dasar Rolling Senam Lantai}

doi

https://doi.org/10.53905/inspiree.v1i1.2

\section{*Ahmad Fajri ${ }^{1 \text { abcde }}$ (1)}

${ }^{1}$ Sekolah Dasar Negeri 005 Langgini, Kecamatan Bangkinang Kota, Riau, Indonesia.

\begin{abstract}
Tujuan Penelitian: Untuk meningkatkan ketangkasan dan keterampilan rangkaian gerakan rolling senam lantai (RSL) kedepan (rolling) dapat dilakukan secara baik dan sempurna maka harus ada sebuah metode mengajar (MD) yang tepat untuk mengajarkan materi ini. Salah satu MD yang penulis anggap tepat adalah metode drill.

Metodologi Penelitian: Dalam penelitian ini menggunakan teknik penelitian tindakan kelas PTK atau Action Research yang mempunyai 2 kali tes (siklus 1 dan sikus 2). Tes yang diambil dari sampel menggunakan tes keterampilan rolling tes pada olahraga senam.

Hasil Penelitian: Dari 32 sampel yang melakukan tes siklus II terdapat sebanyak 27 orang siswa yang berhasil atau tuntas dan 5 orang siswa tidak tuntas dalam melakukan keterampilan RSL kedepan.

Kesimpulan. Keterampilan RSL yang dilakukan oleh siswa semakin meningkat dan sempurna, hal ini menunjukkan hasil yang memuaskan dan terjadi peningkatan yang signifikan
\end{abstract}

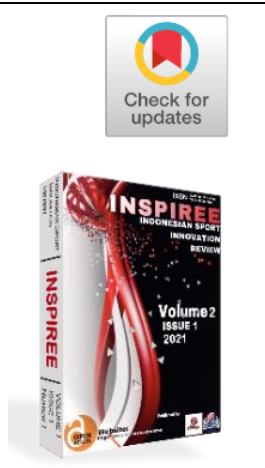

Kata Kunci: rolling pada senam, metode dril, keterampilan dasar

Published: January 27, 2020

PENDAHULUAN

Salah satu cabang olahraga yang dimuat pada kurikulum pendidikan formal kelas 5 sekolah dasar adalah Senam Lantai seperti rolling kedepan. Aminudin (2009) Senam lantai (flour exercise) adalah satu bagian dari rumpun senam. Satrio Ahmad (2007) dalam buku senam mengatakan rolling kedepan adalah di awali dengan sikap berdiri sempurna kemudian jongkok tumpukan kedua telapak tangan disamping telinga, tempelkan dagu kedada.Kedua kaki lurus hingga posisi pinggul lebih tinggi dari bahu, dorong pinggul kedepan hingga seluruh pundak mengenai lantai kemudian dorongkan kedepan dengan tangan teteap bengkok. Pada waktu berrolling hampir keposisi duduk cepat kedua tangan memeluk kedua lutut dan di akhiri dengan posisi jongkok dan kembali keposisi berdiri sempurna.

Satrio Ahmad (2007) dalam buku senam menjelaskan cara melakukan RSL:1) diawali dengan sikap berdiri sempurna kemudian jongkok tumpukan kedua telapak 
tangan disamping telinga siku bengkok, 2) tempelkan dagu kedada, 3) kedua kaki lurus hingga posisi pinggul lebih tinggi dari bahu, 4)dorong pinggul kedepan hingga seluruh pundak mengenai lantai kemudian dorongkan kedepan dengan tangan teteap bengkok, 5) pada waktu berrolling hampir keposisi duduk cepat kedua tangan memeluk kedua lutut dan di akhiri dengan posisi jongkok dan kembali keposisi berdiri sempurna.

Berdasarkan pengalaman dan pengamatan penulis yang merupakan guru pendidikan jasmani di kelas V SDN 005 Langgini Kecamatan Bangkinang Kota dijumpai beberapa masalah. Pada umumnya kurangnya kemampuan siswa dalam menguasai teknik dasar RSL seperti tumpuan tangan tidak tepat, tangan dibuka terlalu lebar atau terlalu sempit dan terlalu jauh dari ujung kaki, tidak menggunakan bahu sebagai tumpuan saat melakukan rolling kedepan tetapi kepalanya, saat berrolling kedepan kaki tidak rapat, tidak ada keberanian siswa untuk melakukan gerakan rolling kedepan dan kurangnya motivasi siswa dalam mengikuti materi rolling kedepan. Permasalahanpermasalahan ini mengindikasikan penulis untuk melakukan perbaikan dalam pembelajaran. Karena sebagian besar keberhasilan ketuntasan siswa dalam menguasai suatu materi belum mencapai KKM yang telah ditentukan yaitu 75 . Ketuntasan keterampilan dasar rolling kedepan (rolling) tercapai apabila siswa mampu memperoleh nilai 75 dari hasil tes rangkaian rolling kedepan, apabila siswa memperoleh nilai dibawah 75 maka siswa tersebut tidak tuntas.

Dengan menganalisa hal diatas, maka penulis tertarik mengadakan suatu tindakan perbaikan pembelajaran guna meningkatkan kemampuan RSL kedepan (rolling) siswa kelas V SDN 005 Langgini Kecamatan Bangkinang Kota melalui MD. Sehingga judul penelitian ini adalah: Upaya Meningkatkan Keterampilan RSL Kedepan ( Rolling ) Melalui MD

MD dalam beberapa sumber juga sering disebut sebagai metode latihan yang disebut juga metode training, yang merupakan suatu cara mengajar untuk memelihara kebiasaan-kebiasaan tertentu, juga sebagai sarana untuk memelihara kebiasaankebiasaan yang baik selain itu, metode ini juga dapat digunakan untuk memperoleh suatu ketangkasan, kesempatan dan keterampilan. Zain dalam Werkanis (2005) mengatakan metode latihan siap atau drill adalah cara mengajar dengan 
Metode Drill Dalam Peningkatan Keterampilan Dasar Rolling Senam Lantai.

mempraktekkan berulang-ulang agar lebih mahir dan terampil untuk melakukannya. Roestiyah (1989:125) mengemukakan bahwa MD adalah suatu teknik yang dapat diartikan sebagai suatu cara mengajar dimana siswa melaksanakan kegiatan-kegiatan latihan, agar siswa memiliki ketangkasan atau keterampilan yang lebih tinggi dari apa yang telah dipelajari. Latihan yang praktis, mudah dilakukan serta teratur melaksanakannya membina anak dalam meningkatkan penguasaan keterampilan itu, bahkan mungkin siswa dapat memiliki ketangkasan itu dengan sempurna.

Adapun tujuan yang akan dicapai pada penulisan penelitian tindakan kelas ini adalah untuk mengetahui peningkatan keterampilan dasar RSL melalui metode drill kelas V SDN 005 Langgini Kecamatan Bangkinang Kota.

\section{METODOLOGI PENELITIAN}

\section{Populasi dan Sampel}

Subjek dalam penelitian ini adalah siswa/siswi kelas V SDN 005 Langgini Kecamatan Bangkinang Kota, Tahun ajaran 2019/2020 dengan jumlah siswa 32 orang terbagi dari 22 orang putra dan 10 orang putri.

Tabel 1. Populasi Siswa SDN 005 Langgini Kecamatan Bangkinang Kota

\begin{tabular}{lcccc}
\hline No & Siswa & Putra & Putri & Jumlah \\
\hline 1. & Kelas V & 22 & 10 & 32 \\
\hline \multicolumn{4}{c}{ Sumber : SDN 005} & Langgini Kecamatan Bangkinang Kota
\end{tabular}

Instrument penelitian yang digunakan dalam penelitian ini adalah rubrik penilaian keterampilan RSL sesuai dengan RPP. Adapun bentuk rubrik penilaian dapat dilihat pada tabel berikut:

Tabel 2. Rubrik Instrumen Penilaian

\begin{tabular}{|c|c|c|c|c|c|}
\hline & \multirow{2}{*}{ Aspek yang dinilai } & \multicolumn{4}{|c|}{ Kualitas Gerak } \\
\hline & & 1 & 2 & 3 & 4 \\
\hline \multicolumn{6}{|c|}{ a. Sikap awal } \\
\hline & 1. siswa jongkok dengan kedua tangan dan kaki rapat & & & & \\
\hline & 2. Kedua telapak tangan diletakkan di matras atau lantai & & & & \\
\hline & 3. Kedua siku tangan dibengkokkan. & & & & \\
\hline & 4. Kepala masuk di antara kedua tangan dan dagu merapat ke dada. & & & & \\
\hline \multicolumn{6}{|c|}{ b. Sikap utama } \\
\hline & $\begin{array}{l}\text { 5. Jatuhkan badan dengan tengkuk leher mendarat dimatras, diikuti punggung dan } \\
\text { pinggul. }\end{array}$ & & & & \\
\hline & $\begin{array}{l}\text { 6. Pada saat berrolling kedepan, kedua tangan cepat memeluk lutut yang dirapatkan } \\
\text { didada. }\end{array}$ & & & & \\
\hline c. & Sikap akhir & & & & \\
\hline & 7. Jongkok dan kembali dengan sikap berdiri sempurna & & & & \\
\hline
\end{tabular}
Jumlah : 
Statistical analysis

Data yang penulis peroleh dikumpulkan dan kemudian di analisis data tersebut sebagai berikut :

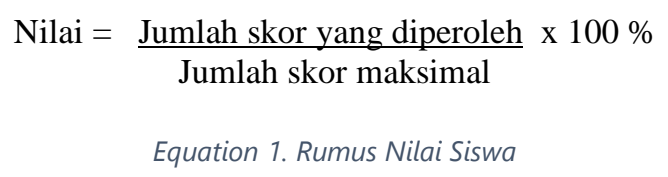

Ketuntasan keterampilan dasar RSL individu tercapai apabila siswa mencapai $75 \%$ dari hasil tes atau nilai 75 , sedangkan ketuntasan klasikal tercapai apabila $80 \%$ dari seluruh siswa mampu melakukan rolling kedepan (Rolling) dengan benar dengan nilai minimum 75 maka kelas itu dikatakan tuntas. Adapun rumus yang dipergunakan untuk menentukan ketuntasan klasikal sebagai berikut :

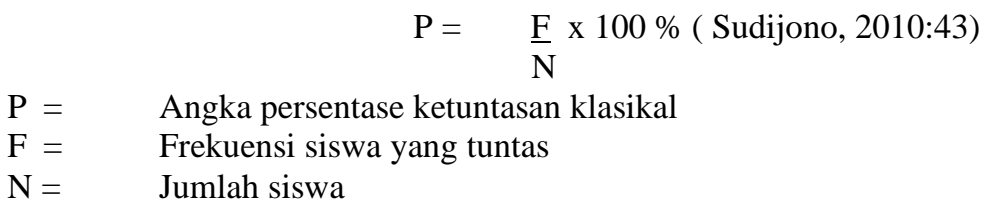

Equation 2. Angka persentase ketuntasan klasikal

\section{HASIL PENELITIAN}

Terlihat data pada lembaran pengamatan itu bahwa pembelajaran yang dilaksanakan belum menunjukkan hasil yang memuaskan dan sangat diperlukan melakukan perbaikan pembelajaran kembali. Untuk lebih jelasnya dapat diperhatikan tabel lembaran pengamatan dibawah ini :

Tabel 3. Distribusi Frekuensi Penilaian Data Awal Keterampilan Dasar Senam Lantai Rolling Kedepan (rolling) Siswa Kelas V SDN 005 Langgini Kecamatan Bangkinang Kota.

\begin{tabular}{cccc}
\hline Perolehan Nilai & Frekuensi & Perasentase & Kategori \\
\hline 90 sd 100 & 0 & 0 & Sangat baik \\
70 sd 89 & 7 & $21,88 \%$ & Baik \\
50 sd 69 & 25 & $78,12 \%$ & Sedang \\
30 sd 49 & 0 & 0 & Kurang \\
10 sd 29 & 0 & 0 & Sangat kurang \\
\hline Jumlah & 32 & $100 \%$ & \\
\hline
\end{tabular}

Sumber: Data Olahan Penelitian 2019

\section{Data Pembelajaran Siklus I}

Selanjutnya dilakukan perencanaan siklus dan melakukan penilaian tes unjuk kerja. Dari hasil penilaian tersebut diperoleh data hasil penilaian dengan perolehan nilai tiap-tiap siswa pada siklus I, untuk lebih jelas dapat dilihat dari penjelasan dibawah ini. Dari hasil penelitian yang dilakukan pada siklus I yakni diperoleh sebanyak 2 orang siswa yang memperoleh nilai 90-100 atau (6,25\%), 24 orang siswa memperoleh nilai 
70-89 atau (75\%), dan 6 orang siswa memperoleh nilai 50-69 atau (18,75\%). Dibawah ini merupakan tabel distribusi frekuensi penilaian keterampilan dasar senam lantai rolling kedepan (rolling) siklus I.

Tabel 4. Distribusi Frekuensi Penilaian Data Siklus I Keterampilan Dasar Senam Lantai Rolling Kedepan (rolling) Siswa Kelas V SDN 005 Langgini Kecamatan Bangkinang Kota.

\begin{tabular}{|c|c|c|c|}
\hline Perolehan Nilai & Frekuensi & Perasentase & Kategori \\
\hline $90 \mathrm{sd} 100$ & 2 & $6,25 \%$ & Sangat baik \\
\hline 70 sd 89 & 24 & $75 \%$ & Baik \\
\hline 50 sd 69 & 6 & $18,75 \%$ & Sedang \\
\hline 30 sd 49 & 0 & 0 & Kurang \\
\hline 10 sd 29 & 0 & 0 & Sangat kurang \\
\hline Jumlah & 32 & $100 \%$ & \\
\hline
\end{tabular}

Sumber: Data Olahan Penelitian 2019

\section{Data Pembelajaran Siklus II}

Selanjutnya dilakukan perencanaan siklus dan melakukan penilaian tes unjuk kerja. Dari hasil penilaian tersebut diperoleh data hasil penilaian dengan perolehan nilai tiap-tiap siswa pada siklus II, untuk lebih jelas dapat dilihat dari penjelasan dibawah ini.

Dari hasil penelitian yang dilakukan pada siklus II yakni diperoleh sebanyak 14 orang yang memperoleh nilai $90-100$ atau $(43,75 \%)$, dan 18 orang yang memperoleh nilai 70-89 atau (56,25\%). Untuk lebih jelas dapat dilihat pada lampiran 5. Dibawah ini merupakan tabel distribusi frekuensi penilaian keterampilan dasar senam lantai rolling kedepan (rolling) siklus II.

Tabel 5. Distribusi Frekuensi Penilaian Data Siklus I/ Keterampilan Dasar RSL Siswa Kelas V SDN 005 Langgini Kecamatan Bangkinang Kota.

\begin{tabular}{lccc}
\hline Perolehan Nilai & Frekuensi & Perasentase & Kategori \\
\hline 90 sd 100 & 14 & $43,75 \%$ & Sangat baik \\
70 sd 89 & 18 & $56,25 \%$ & Baik \\
50 sd 69 & 0 & 0 & Sedang \\
30 sd 49 & 0 & 0 & Kurang \\
10 sd 29 & 0 & 0 & Sangat kurang \\
\hline Jumlah & 32 & $100 \%$ &
\end{tabular}

Berdasarkan deskripsi data yang dipaparkan diatas, maka dapat dilihat bahwa dengan penerapan MD secara baik dan benar, maka aktivitas siswa menjadi lebih aktif dan pada gilirannya meningkatkan hasil belajar keterampilan RSL lebih baik. Untuk data awal menunjukkan bahwa dari 32 murid yang tuntas tertdapat 7 orang atau (21,88\%), tidak tuntas 25 orang $(78,12 \%)$. Siklus I menunjukkan kategori tuntas terdapat 23 orang $(71,88 \%)$, tidak tuntas 9 orang $(28,12 \%)$. Sedangkan pada siklus II murid yang tuntas sebanyak 27 murid (84,37\%) dan tidak tuntas sebanyak 5 murid $(15,62 \%)$. 
Untuk lebih jelas mengenai peningkatan hasil belajar siswa dalam keterampilan dasar RSL dapat dilihat keterangan hasil belajar siswa dalam menggunakan MD dari data awal, siklus I, dan siklus II pada tabel 6 dibawah ini.

Tabel 6. Perbandingan Hasil Belajar Siswa Dalam Menggunakan Metode Drill Keterampilan Dasar Senam Lantai Rolling Kedepan (Rolling).

\begin{tabular}{lcccc}
\hline Kategori & Data Awal (\%) & Siklus I (\%) & Siklus II (\%) & Ket. \\
\hline Tuntas & $7(21,88 \%)$ & $23(71,88 \%)$ & $27(84,37 \%)$ & $5(15,62 \%)$ \\
Tidak Tuntas & $25(78,12 \%)$ & $9(28,12 \%)$ & Adanya Peningkatan & \\
\hline Jumlah & $32(100 \%)$ & $32(100 \%)$ & $32(100 \%)$ & \\
\hline
\end{tabular}

Sumber : Data Olahan Penelitian 2019

Dari tabel diatas, dapat disimpulkan bahwa pada kegiatan data awal siswa yang tuntas adalah sebanyak 7 orang, dan yang tidak tuntas sebanyak 25 orang, pada siklus I siswa yang tuntas adalah sebanyak 23 orang dan yang tidak tuntas sebanyak 9 orang, dan pada siklus II siswa yang tuntas sebanyak 27 orang dan yang tidak tuntas sebanyak 5 orang. Dengan demikian dapat disimpulkan terjadi peningkatan hasil belajar siswa dari setiap jenjang siklus. Berdasarkan hasil belajar yang diperoleh siswa dalam keterampilan dasar RSL, dapat dilihat dari selisih peningkatan hasil belajar siswa dalam menggunakan MD pada gambar 4 dibawah ini.

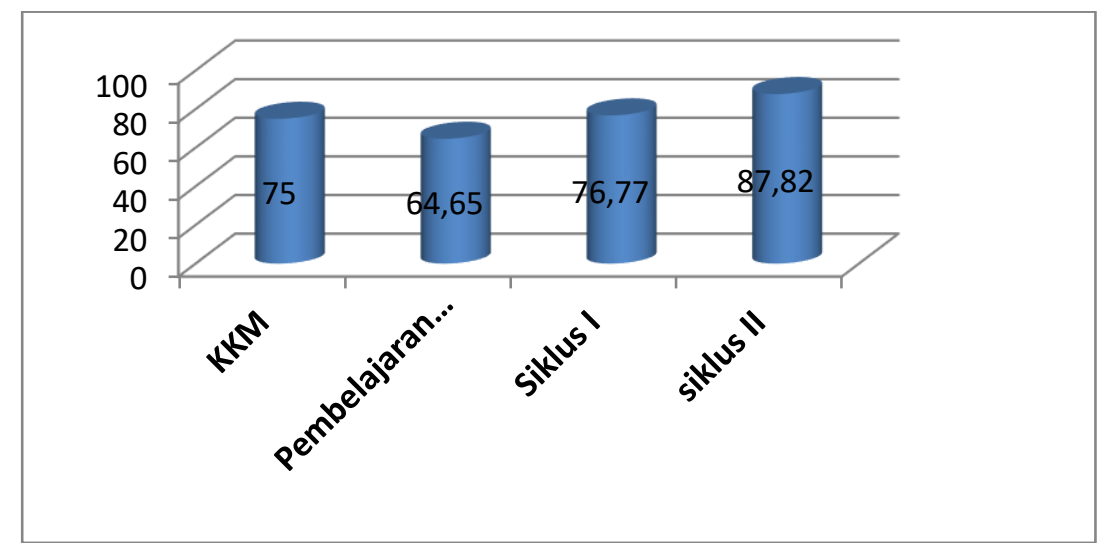

Gambar 1. Selisih Peningkatan Hasil Belajar Siswa Dalam Menggunakan Penerapan MD Keterampilan RSL.

Dari grafik diatas, dapat diketahui bahwa denan KKM sebesar 75, pencapaian siSwa pada kegiatan data awal adalah sebesar $64,65 \%$, siklus I sebesar $76,77 \%$ dan siklus II sebesar $87,82 \%$, maka pada tiap siklus terjadi peningkatan yang singnifikan.

\section{PEMBAHASAN}

Dalam meningkatkan ketangkasan dan keterampilan rangkaian gerakan RSL dapat dilakukan secara baik dan sempurna maka harus ada sebuah MD yang tepat untuk mengajarkan materi ini. Salah satu metode mengajar yang penulis anggap tepat 
adalah metode drill. Karena metode ini sangat cocok untuk memperoleh suatu keterampilan yang dipelajari. Hal ini dikarenakan MD adalah cara mengajar dengan mempraktekkan berulang-ulang agar lebih mahir dan terampil untuk melakukannya. Maka dengan demikian semakin sering siswa mempraktekkan gerakan rolling kedepan semakin meningkat dan sempurna keterampilan dan ketangkasan gerakan rolling kedepan yang dilakukannya.

Berdasarkan deskripsi data hasil penelitian dimulai dari data pembelajaran awal hingga melakukan perbaikan pembelajaran, kesemua itu hasil dari pengamatan penulis dalam jalannya penelitian tindakan kelas ini. Maka dapat disimpulkan perbaikan pembelajaran keterampilan dasar RSL dengan indikator rolling kedepan (rolling) yang telah dilaksanakan sudah menunjukkan hasil yang baik, hal ini dapat di buktikan dengan melihat dan mengamati hasil belajar siswa dalam partisifasinya saat mengikuti pembelajaran, baik pada perbaikan pembelajaran siklus pertama maupun siklus kedua.

Dari 32 sampel yang melakukan tes siklus II terdapat sebanyak 27 orang siswa yang berhasil atau tuntas dan 5 orang siswa tidak tuntas dalam melakukan keterampilan RSL. Dengan demikian penerapan MD dalam pembelajaran berpengaruh dalam meningkatkan hasil belajar keterampilan RSL kelas V SDN 005 Langgini Kecamatan Bangkinang Kota, hal ini terlihat sangat berpengaruh saat RSL kedepan yang dilakukan oleh siswa semakin meningkat dan sempurna, hal ini menunjukkan hasil yang memuaskan dan terjadi peningkatan yang signifikan.

\section{KESIMPULAN}

Berdasarkan hasil penelitian, maka dapat diambil kesimpulan penelitian sebagai berikut: Penerapan MD dapat meningkatkan hasil belajar keterampilan dasar RSL kedepan siswa kelas V SDN 005 Langgini Kecamatan Bangkinang Kota. Sehingga MD disarankan dan diajukan untuk meningkatkan keberhasilan dalam proses belajarmengajar mata pelajaran olaharaga senam pada usia anak sekolah dasar.

\section{UCAPAN TERIMAKASIH}

Penulis dengan ini mengucapkan terima kasih kepada seluruh peserta dan semua orang yang membantu dalam penelitian ini. 


\section{DAFTAR PUSTAKA}

Aminudin, 2009, Praktek Anake Teknik Senam, CV. Citralab, Bandung.

Arief, Kurniawan, Khairul Hadziq, 2010, Bugar dan Sehat Melatih Kondisi Fisik Senam, CV. Citralab, Bandung.

Arikunto Suharsimi, Suhardjono dan Supardi, 2010, Penelitian Tindakan Kelas, Bumi Aksara, Jakarta.

Dadan heryana, Giri Verianti, 2010, Pendidikan Jasmani Olahraga dan Kesehatan Kelas V, CV. Putra Nugraha, Jakarta.

Dinn, Wahyudin, Supriadi, Ishak Abduhak, 2007, Pengantar Pendidikan, Universitas Terbuka, Jakarta.

Edang Widyastuti, Agus Suci, 2010, Jasmani Olahraga dan Kesehatan Kelas VI, CV. Putra Nugraha, Jakarta.

IGAK Wardhani, dkk, 2007, Penelitian Tindakan Kelas, Universitas Terbuka, Jakarta Rusmin Pagat, Naga Nasution, Thamrin Nasution, Saroha Mahulae, 1996, Pendidikan Jasmani Olahraga dan Kesehatan kelas V, CV. Budi Medan, Medan.

Roestiyah, NK, 1989, Strategi Belaja Mengajar, Bina Aksara, Jakarta.

Satrio, Ahmad Y, 2007, Senam, PT Indah Jaya Adipratama, Bandung

Sudijono, Anas, 2004, Pengantar Statistik Pendidikan, Raja Grafindo Persada. Jakarta

Tim Abdi Guru, 2007, Pendidikan Jasmani, olahraga dan Kesehatan kelas V, Erlangga, Jakarta.

Werkanis. AS, Marliyus Hamad, 2005, Strategi mengajar, Sutra Benta Perkasa, Riau. 


\section{LAMPIRAN}

\section{Informasi Tentang Penulis:}

\section{Muhammad Iqbal, M.Pd:}

Email: Jnurti@yahoo.com; https://orcid.org/0000-0002-5805-260X; SDN 005 Langgini,

Kecamatan Bangkinang Kota; Alamat: Jalan Pramuka Kelurahan langgini, Bangkinang Kota, Kabupaten Kampar, Riau, Indonesia . 28412, Indonesia. 